\title{
Shear Stress Analysis and Crack Prevention Measures for a Concrete-Face Rockfill Dam, Advanced Construction of a First-Stage Face Slab, and a First-Stage Face Slab in Advanced Reservoir Water Storage
}

\author{
Kongzhong Hu, Jiankang Chen $(\mathbb{D}$, and Dong Wang \\ College of Water Resource \& Hydropower, Sichuan University, Chengdu 610065, Sichuan, China \\ Correspondence should be addressed to Jiankang Chen; 2275764763@qq.com
}

Received 7 March 2018; Accepted 10 July 2018; Published 24 September 2018

Academic Editor: Dongsheng Li

Copyright $\odot 2018$ Kongzhong Hu et al. This is an open access article distributed under the Creative Commons Attribution License, which permits unrestricted use, distribution, and reproduction in any medium, provided the original work is properly cited.

\begin{abstract}
Due to the demand in flood season for power generation, the first-stage face slab of a high concrete-face rockfill dam often must be constructed ahead of schedule, and advanced water storage is needed for the reservoir. Since the dam-body filling has not yet been completed at this point, the internal stress of the first-stage face slab is more complicated than that of normal construction. Taking Buxi Power Station as an example, the first-stage face slab temporary construction seam showed large areas of shear stress damage during the rise in reservoir water levels during the second segment of the second construction stage. The concrete-face slab showed large-piece brittle bulging, and the steel rebar was exposed and developed contortional deformation. Based on the monitoring data for Buxi Power Station along with the first-stage fracture characteristics of Shuibuya concrete face, this paper applied a numerical analysis to conduct research on the causes of fracture mechanics. The results indicate that the cracks occurred on the face slab during the second segment of second-stage water storage primarily due to the advanced concrete pouring of the first-stage face slab; during the first stage of reservoir water storage, the internal stress of the first-stage face slab was not reduced or eliminated prior to second-stage face slab pouring. Thus, with the rise in the reservoir water level, the shear stress increased continuously, eventually leading to partial large-scale shear stress failure of the first-stage face slab. The research results provide important references for the design and construction of concrete-face rockfill dams.
\end{abstract}

\section{Introduction}

Concrete-face rockfill dams have advantages such as their large scale, low interior stress, and construction efficiency attributable to the use of large construction equipment $[1,2]$. Therefore, the number of dams of this type is rapidly increasing. A few high concrete-face rockfill dams have been constructed in China [3-7]. At present, the $233 \mathrm{~m}$ Shuibuya concrete-face rockfill dam has the largest dam height of any concrete-face rockfill dam in the world $[8,9]$.

Concrete-face crack is a relatively common problem. To reduce face slab cracks, the concrete slab should be completed in one pouring after the settlement of the dam body under ideal conditions $[10,11]$. However, the concrete slab is often poured in several stages a few months after the completion of rock mass fill in the actual construction. In particular, for the high concrete-face rockfill dam, due to the demand in flood season for power generation, the first-stage face slab must be constructed beforehand, and advance water storage is needed for reservoir [12-15]. For instance, for the $135.8 \mathrm{~m}$ Buxi and the $233 \mathrm{~m}$ Shuibuya concrete-face rockfill dam, before the dam body was completely filled to the top, the construction of the first-stage concrete slab and first-stage reservoir water storage had already begun.

The interface between the rockfill body and the slab is provided with a cushion and transition layer, and the upper surface of the cushion layer is coated with special materials, such as asphalt, that reduce friction. In the advance construction of the first-stage face slab and reservoir water storage, due to the influence of water pressure at the 
reservoir water level along with settlement and deformation in the interior of the rockfill mass, the internal stress of the concrete slab will undergo certain changes. Because the face slab is simply supported by the dam body and the first-stage water storage level is lower than the temporary construction seam level, at this point, the water pressure effect and settlement deformation of dam body will appear on the firststage face slab at the reservoir level underneath the water surface. Above the water surface, the face slab tilts upward, and disengagement occurs between the face slab and the cushion layer. If the second-stage face slab cannot successfully detract the internal stress and other adverse effects from the first-stage face slab prior to concrete pouring, then after the second-stage slab pouring and second-stage water storage, the internal stress of the first-stage face slab will be redistributed again, causing a negative effect on the first-stage face slab.

The concrete slab has a flexible, thin plate structure [16]. The internal reinforcement of the first-stage slab is equipped with a single layer of steel mesh along the middle layer, such as that of Buxi Power Station. In addition, the outer edge within the slab is provided with double steel mesh, like that of the Shuibuya Power Station. The analysis of structural stress characteristics reveals that double-layer reinforcement is more advantageous than single-layer reinforcement in structural shearing resistance [17]. However, it is not absolutely perfect. Figure 1 shows the on-site drawing of the Shuibuya slab crack. Figure 2 displays the on-site photo of the slab penetrating the crack for Buxi Power Station. The figure indicates that because Buxi Power Station is equipped with single-layer steel mesh, its shearing resistance is weak. Thus, the first-stage slab presents a large extent of shearing failure. The slab is brittle, bulging, and broken into large pieces, and the steel rebar undergoes distortion and deformation. Although Shuibuya shows no large-scale shearing failure, the cracks in the upper and lower layer also appear in the relatively concentrated region, and the cracks display an "I" shape [18].

Both slabs present concentrated crack regions with limited width at the top and bottom [7, 19]. This indicates that when the first-stage slab launched advance construction and reservoir water is stored beforehand, internal stress has its own characteristics. At this point, if only the influence of rockfill body deformation and settlement on slab stress is considered, then obviously it has been unable to adapt to the force characteristics of the slab [20].

Based on the above description and the monitoring data of the slab for Buxi Power Station, this paper used a comparative analysis method that applies Ansys finite element software to conduct mechanical-cause research on the slab cracks at Buxi Power Station to determine the cause of brittle failure of the first-stage slab during advance construction and reservoir water storage, presenting design ideas along with corresponding structural measures to prevent the occurrence of cracks [21].

\section{Project Overview}

Buxi Power Plant is located in Muli County, Liangshan Prefecture, Sichuan Province, China. The dam is situated on

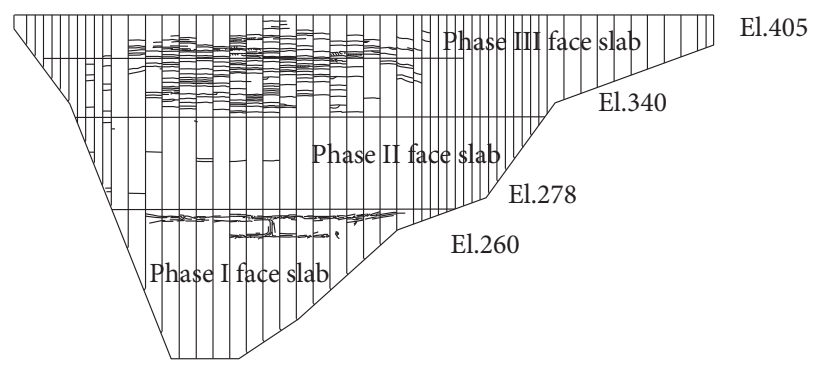

Figure 1: Sketch of the slab crack distribution at Shuibuya Power Station.

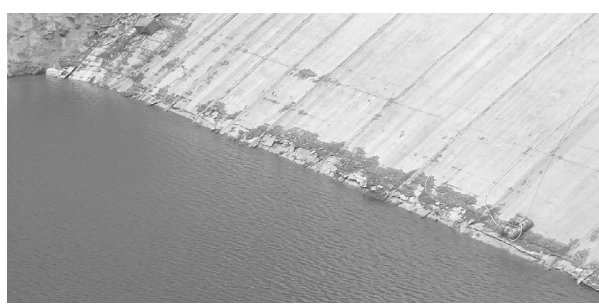

Figure 2: Image of slab cracks at Buxi Power Station.

the first-order tributary Yazui River on the right bank of the Yalong River and is the "leading" reservoir power plant in cascaded hydropower planning along the Yazui River. The power plant is located $53 \mathrm{~km}$ from the seat of Muli County and $318 \mathrm{~km}$ from the city of Xichang. The river basin upstream of the reservoir measures approximately $409 \mathrm{~km}^{2}[22,23]$.

This project primarily consists of a reinforced-concreteface rockfill dam, a sluice, a spillway tunnel, a water diversion structure, and a power plant. The normal reservoir impoundment elevation is $3300 \mathrm{~m}$, the check flood elevation is $3302.55 \mathrm{~m}$, and the dead water elevation is $3240 \mathrm{~m}$. The dam capacity is $1986 \mathrm{~m}^{3}$, and the reservoir regulating capacity is $2.1649 \times 10^{8} \mathrm{~m}^{3}$.

The water-retaining structure is the concrete-face rockfill dam. The maximum dam height is $135.80 \mathrm{~m}$, the dam's crest elevation is $3305.80 \mathrm{~m}$, the top width is $12 \mathrm{~m}$, the upstream slope gradient is $1: 1.4$, and the downstream slope gradient is $1: 1.45$ above the $3263.00 \mathrm{~m}$ elevation and $1: 1.5$ below the $3263.00 \mathrm{~m}$ elevation. Dam seepage control is provided by the concrete face slab. There are 33 concrete-face slabs, and their total area is $3.7 \times 10^{4} \mathrm{~m}^{3}$. The concrete for the face was placed in two phases: the portion below the $3259 \mathrm{~m}$ elevation was placed in phase I, and the portion above the $3259 \mathrm{~m}$ elevation was placed in phase II (Figure 3 ).

The primary monitoring instruments deployed on the concrete face consist of a void meter, a rebar meter, and a nonstress meter (Figure 4). A water measurement weir is deployed downstream of the dam.

\section{Construction Process}

The main construction of the Buxi Power Plant dam officially commenced on March 1, 2008. Excavation for the dam foundation and left and right bank slopes commenced on April 1, 2008. On April 23, 2008, the river course was closed. 


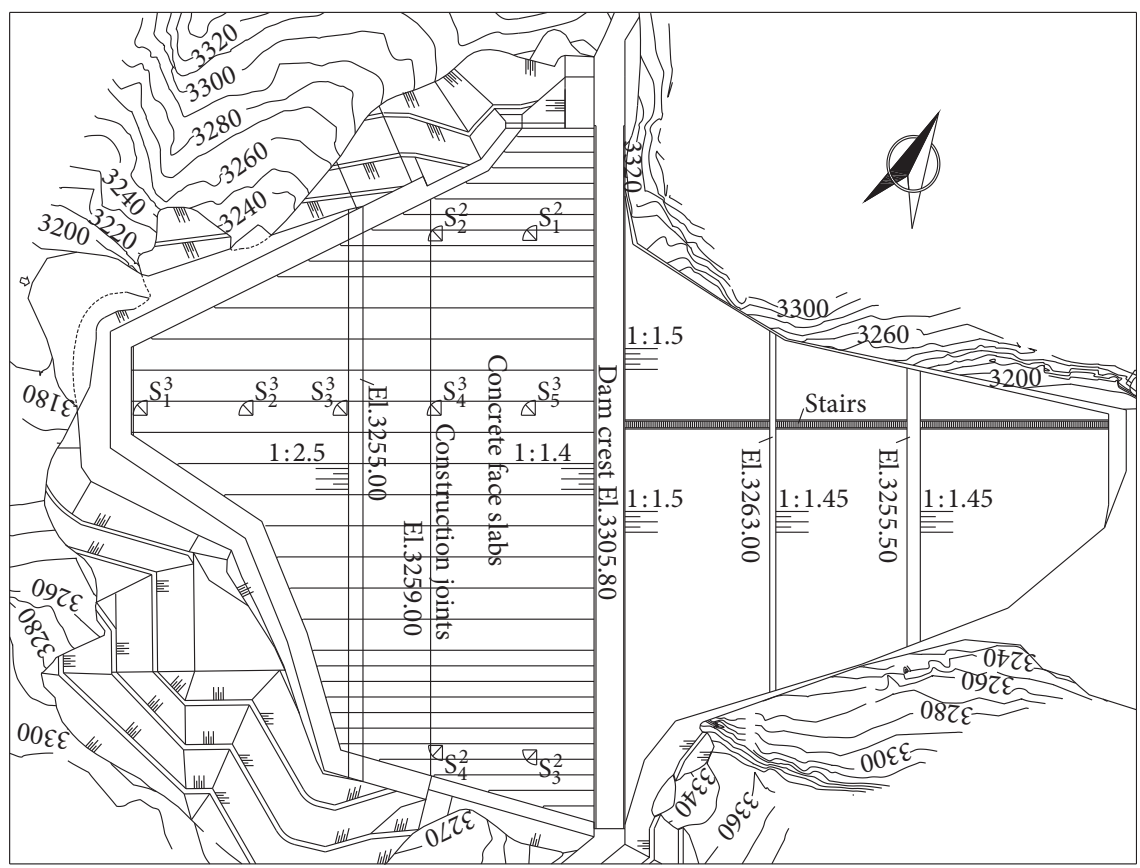

Figure 3: Dam plan layout and concrete-face rebar meter layout.

On October 18, 2008, concrete placement for the toe slab commenced. On November 13, 2008, dam filling commenced. On December 26, 2009, filling to the $3262 \mathrm{~m}$ elevation was completed. Between August 1 and September 18, 2010, filling for the blanket in front of the dam was completed. On February 10, 2011, dam filling to the dam's design elevation of $3303 \mathrm{~m}$ was completed. After phase I, there were 25 concrete-face slabs, and the concrete face spanned from $3170 \mathrm{~m}$ to $3259 \mathrm{~m}$. Pouring started on April 14, 2010, and was completed on August 31, 2010. After phase II, there were 33 concrete-face slabs, and the concrete face spanned from $3259 \mathrm{~m}$ to $3303 \mathrm{~m}$. Pouring started on April 13, 2011, and was completed on June 29, 2011.

\section{Cause Analysis of Concrete-Face Fracturing Based on Monitoring Data}

4.1. Slab Fracturing. When phase I of the face construction was completed, inspection of slab fractures in February 2011 resulted in identification of 46 fractures in the concrete face. All were horizontal fractures. Six fractures were $0.15 \mathrm{~mm}$ or greater in width, and 2 fractures were $0.2 \mathrm{~mm}$ or greater in width. During the phase II face impoundment, 12 microfractures were discovered. When the dam impoundment reached $3297.5 \mathrm{~m}$ in elevation, 5 microfractures were discovered between elevations of $3297.5 \mathrm{~m}$ and $3300 \mathrm{~m}$. Because the fractures were small, they were repaired with HK-G epoxy grouting material and PUA-75 polyurea elastic coating and surface sealing material.

Photographs of horizontal fractures and extrusional joint deformation are presented in Figures 5 and 6.

4.2. Face Slab Stress. Monitoring of the concrete face focused primarily on stress and strain. Analysis of the monitoring

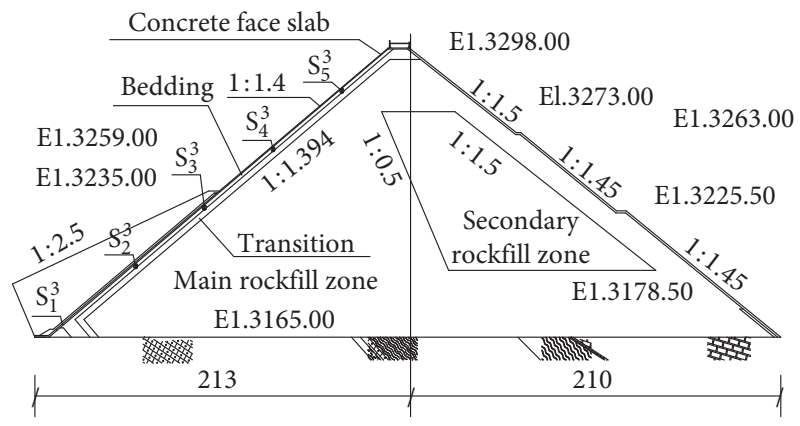

Figure 4: Typical dam section and concrete-face rebar meter layout.

data indicated that data from the concrete-face rebar and from biaxial and triaxial strain meters were normal. Data from the concrete-face strain meter were normal, and the maximum strain was $600 \mu \varepsilon$. However, the rebar horizontal and vertical stresses at the $3255 \mathrm{~m}$ elevation showed clear variations when the water level rose during phase II, stage II. The corresponding time series are shown in Figures 7 and 8.

4.3. Dam-Body Separation. Void meters on the concrete face were deployed mainly at elevations of $3255 \mathrm{~m}$ and $3283 \mathrm{~m}$. The data from the void meter at the $3255 \mathrm{~m}$ elevation showed no marked separation. Due to the reservoir water level, significant changes were recorded by the void meter at the $3283 \mathrm{~m}$ elevation. In particular, during the phase II, stage II reservoir impoundment, a significant, abrupt change coincided in time with an abrupt change detected by the rebar meter at the $3255 \mathrm{~m}$ elevation. Time series of the monitoring data are shown in Figures 9 and 10. 


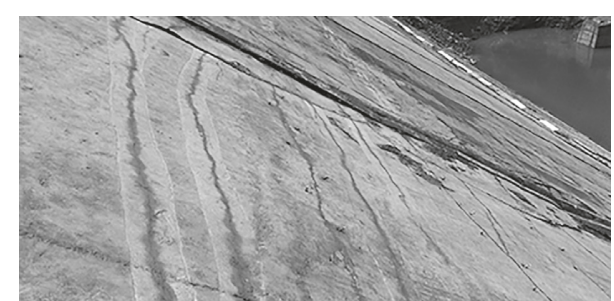

FIgURE 5: Horizontal fractures in the concrete-face slab.

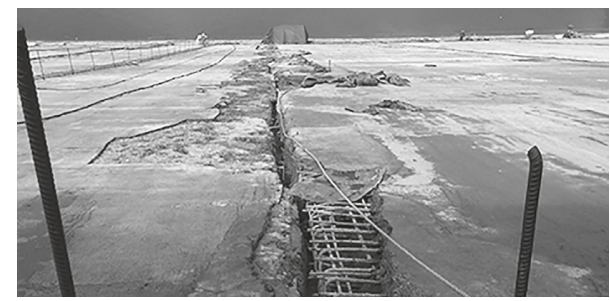

Figure 6: Extrusional deformation along the slab joints.

4.4. Dam-Body Seepage. Phase I impoundment occurred on September 28, 2010. As the water level rose, significant seepage of approximately $600-700 \mathrm{~L} / \mathrm{s}$ from bedrock fractures in the slope toe behind the dam occurred. By June 15, 2012, the reservoir water level had risen to $3281.25 \mathrm{~m}$, and the seepage measured $900 \mathrm{~L} / \mathrm{s}$. By November 18, 2012, the water level had risen to $3298.64 \mathrm{~m}$, and the seepage measured $1645 \mathrm{~L} / \mathrm{s}$. At the beginning of 2013, the seepage reached $2000 \mathrm{~L} / \mathrm{s}$, and the seepage measured at the weir during the phase II, stage II reservoir impoundment showed a trend of significant increase. Variations in the seepage measured at the weir are shown in Figure 11.

The dam at the Buxi Power Plant is an irregular, deep U-shaped structure whose left bank is steep and whose right bank is a distinct staircase terrace. Due to this configuration, the rockfill body on both sides tends to develop extrusional deformation toward the river's center. Therefore, deformation along slab joints is normal. Analysis of images of the deformation suggests that the total deformation is within a reasonable range. However, the horizontal fracturing and extrusional joint deformation were insufficient to cause the sudden increase in seepage after August 2012. Analysis results suggest either significant failure elsewhere or significant seepage within the dam body. Analysis of horizontal stress and vertical stress at $3255 \mathrm{~m}$ shows that, by approximately July 2012, the concrete face experienced a significant, abrupt change, and that time point exactly coincides with the reservoir impoundment in phase II, stage II.

In April 2014, the reservoir was lowered. When the water level dropped below the elevation of the temporary construction joint between phases I and II, severe deformation of the concrete face at the river centerline was observed near the temporary construction joint with phase I. Bulging of the concrete created large blocks representing brittle failure, and rebar was exposed and developed contortional deformation. This fracturing had a widespread effect. Except for face 28 on the left and faces 4,5 , and 6 on the right displaying no marked fracturing, fracturing almost penetrated the temporary construction joints between the other concrete faces of phases I and II. Analysis suggests that the main cause of the sudden increase in seepage measured at the weir after August 2012 was that water flowed downstream through this seepage channel in the dam body.

Figure 12 shows the location of slab fracturing after the reservoir lowering. Local failure near the temporary construction joint between phases I and II is shown in Figure 13.

Analysis of the concrete face stress monitoring data and photographs suggests that the fracture deformation of the face near the temporary construction joint in the phase I portion was likely caused by a specific mechanism. It appears that the reservoir water level during phase I was high and that stress within the concrete face was substantial. Before the placement of concrete in phase II, the interior stress in the phase I face had not dissipated sufficiently. As the water level rose in phase II, this stress generated significant shear stress near the temporary construction joints between phases I and II, which finally led to shear stress failure in the concrete face.

\section{Analysis of the Mechanical Cause of Face Fracturing}

5.1. Computation Theory. The rockfill dam face construction and impoundment were performed in phases. To investigate the effects of this multistage construction and impoundment on the slab stress, a three-variable creep computation model was used, represented by the following equation [24-27]:

$$
\varepsilon=\frac{\sigma}{E}=\varepsilon_{i}+\varepsilon_{t}=\frac{\sigma}{E_{1}}+\frac{\sigma}{E_{2}}\left(1-e^{-\left(E_{2} / \eta\right) t}\right),
$$

where $\sigma$ is the stress, $E_{1}$ is the elastic modulus of the material, $E_{2}$ is the viscous elastic modulus in the Kelvin model, and $\eta$ is the viscous coefficient in the Kelvin model. The derivative of the above formula with respect to time $t$ is as follows:

$$
\frac{\partial \varepsilon}{\partial t}=\dot{\varepsilon}_{t}=a \varepsilon_{\mathrm{f}} e^{-a t}=a \varepsilon_{\mathrm{f}}\left(1-\frac{\varepsilon_{t}}{\varepsilon_{\mathrm{f}}}\right)=a\left(\varepsilon_{\mathrm{f}}-\varepsilon_{t}\right) .
$$

The strain tensor is decomposed into the volumetric strain and the deviatoric strain:

$$
\begin{aligned}
& \dot{\varepsilon}_{\mathrm{vt}}=a \varepsilon_{\mathrm{vf}}\left(1-\frac{\varepsilon_{\mathrm{vt}}}{\varepsilon_{\mathrm{vf}}}\right), \\
& \dot{V}_{t}=a V_{\mathrm{f}}\left(1-\frac{V_{t}}{V_{\mathrm{f}}}\right),
\end{aligned}
$$

where $\varepsilon_{\mathrm{vf}}$ is the final body rheological value and $V_{\mathrm{f}}$ is the final shear rheological value.

In the Prandtl-Reuss assumption, the strain rate tensor is calculated using the following formula:

$$
\left\{\dot{\varepsilon}_{t}\right\}=\frac{1}{3} \dot{\varepsilon}_{\mathrm{vt}}\{I\}+\dot{V}_{t} \frac{\{S\}}{\sigma_{\mathrm{s}}},
$$

where $\{S\}$ is the deviatoric stress tensor, $\{I\}$ is the unit tensor, and $\sigma_{s}$ is the generalized shear stress. The rheological value is treated as the initial strain. Substitution yields the following equation: 


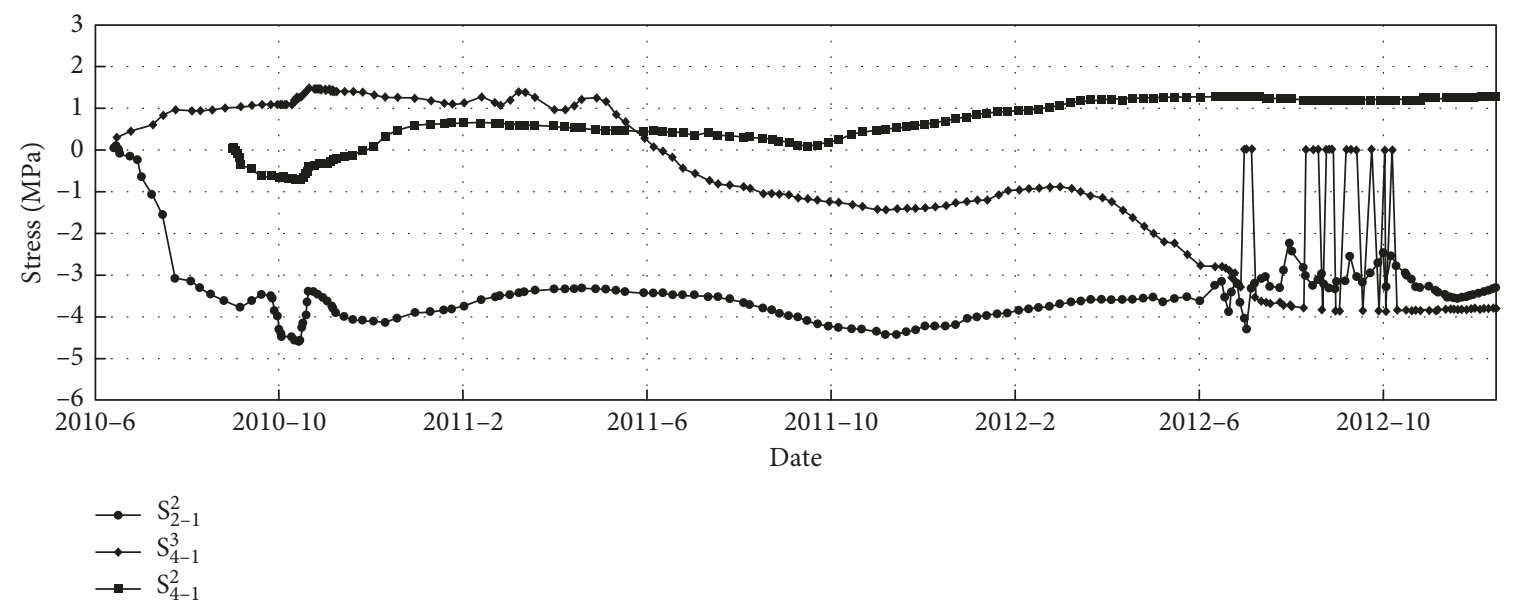

FIGURE 7: Rebar horizontal stress time series at the $3255 \mathrm{~m}$ elevation.

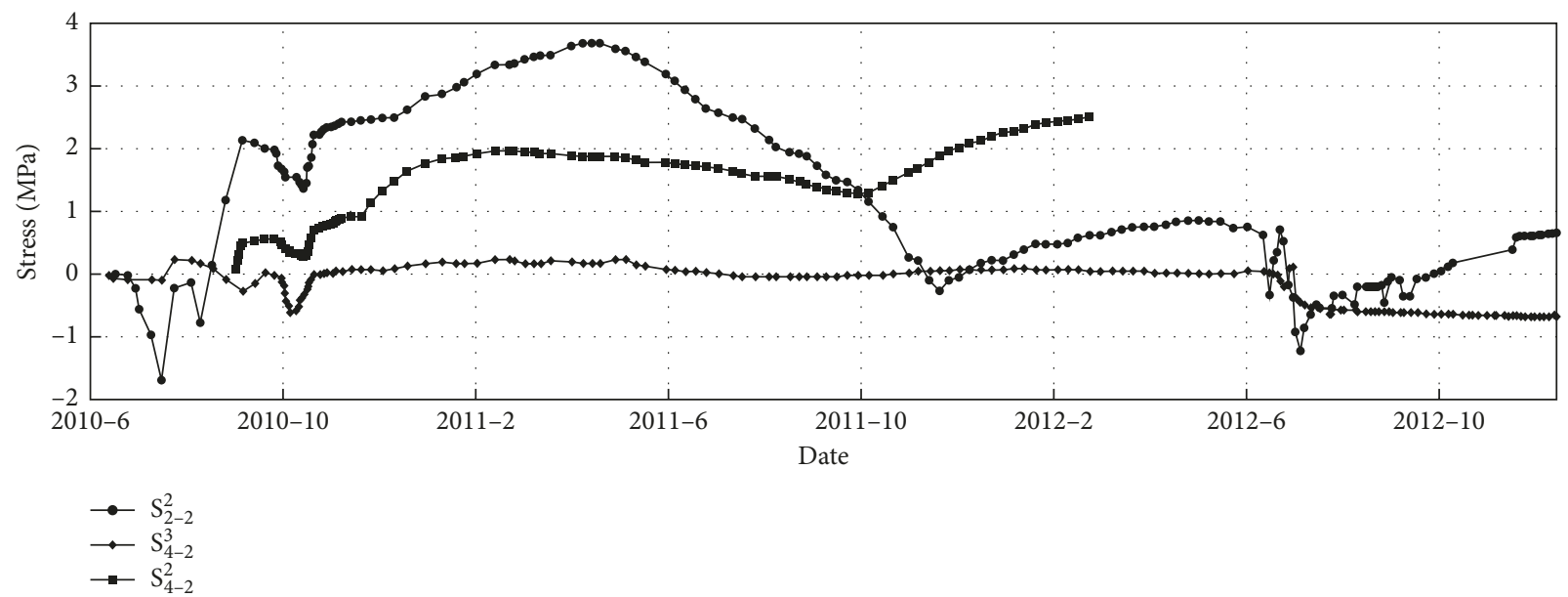

Figure 8: Rebar vertical stress time series at the $3255 \mathrm{~m}$ elevation.

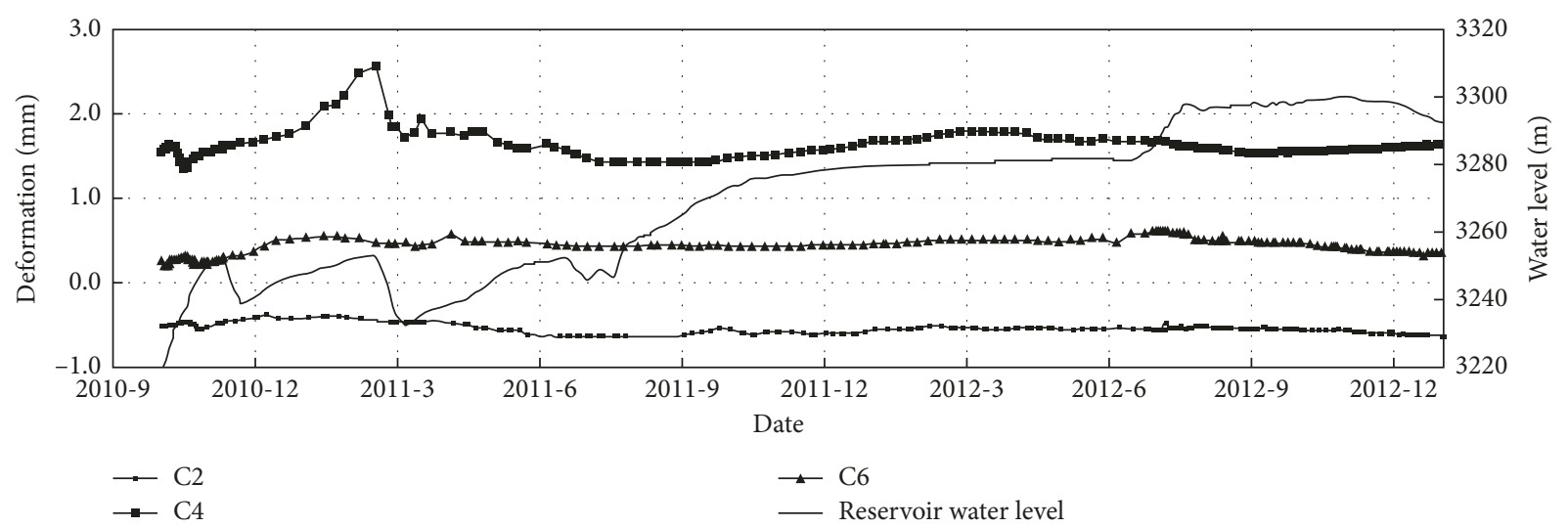

Figure 9: Void deformation time series at the $3255 \mathrm{~m}$ elevation. 


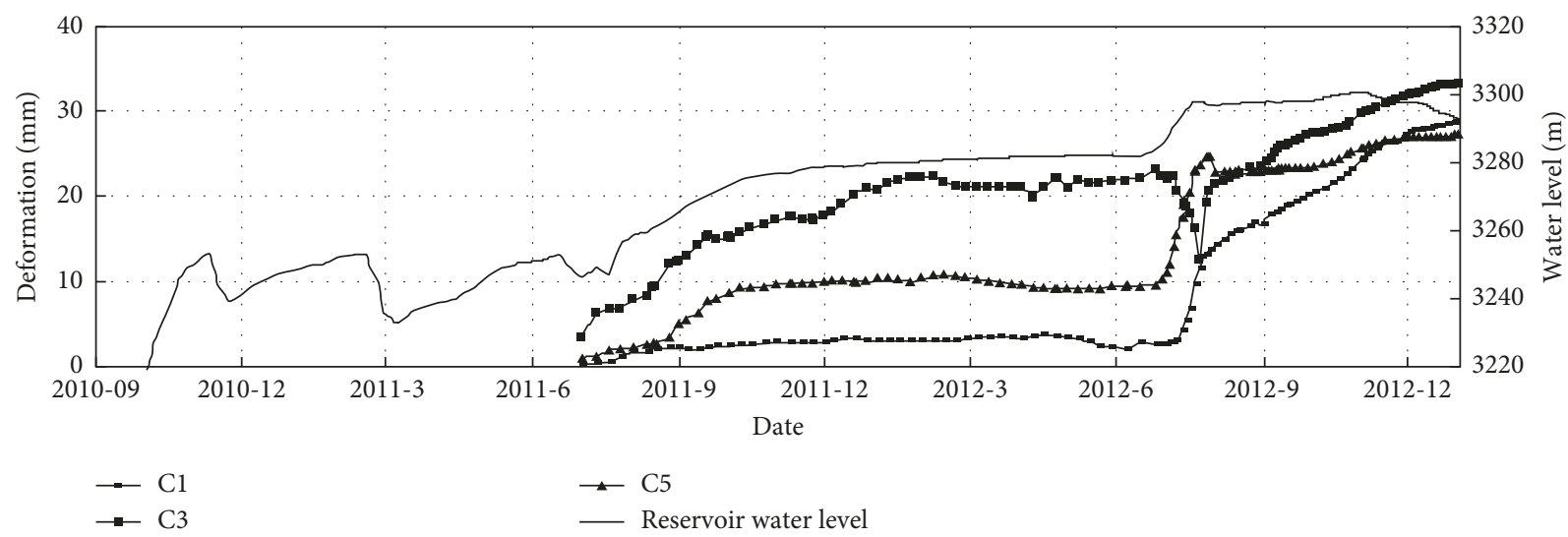

FIgURE 10: Void deformation time series at the $3283 \mathrm{~m}$ elevation.

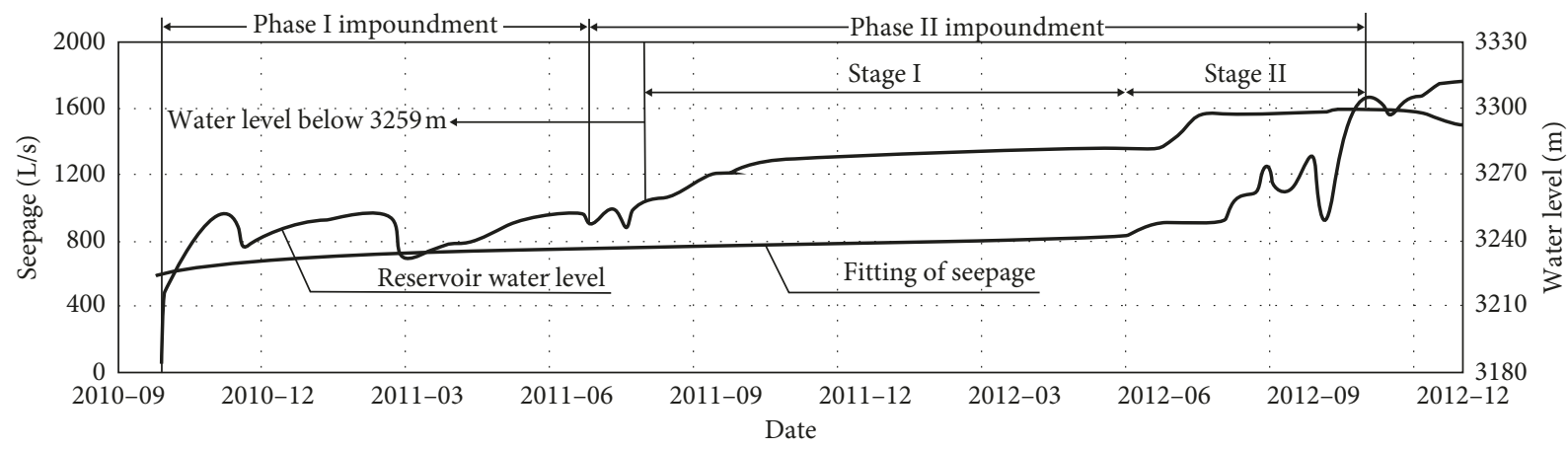

FIgURE 11: Variations in seepage measured at the weir.

$$
\begin{aligned}
\left\{\varepsilon_{t}\right\}= & \frac{1}{3} \varepsilon_{\mathrm{vt}}\{I\}+V_{t} \frac{\{S\}}{\sigma_{\mathrm{s}}}=\frac{1}{3}\left[e^{-a t}+b\left(\frac{\sigma_{3}}{p_{\mathrm{a}}}\right)^{m}\right]\{I\} \\
& +\left[e^{-a t}+d \frac{S_{1}}{1-S_{1}}\right] \frac{\{S\}}{\sigma_{\mathrm{s}}},
\end{aligned}
$$

where $b$ is the final volume rheological variable when $\sigma_{3}=p_{\mathrm{a}}, V_{\mathrm{f}}$ is the final shear rheological variable when $S_{1}=0.5$, and $\alpha$ is the portion of the rheological variable on day one.

This formula is substituted into the rheological model, which yields the following equation:

$$
\begin{aligned}
\{\varepsilon\}=\frac{\sigma}{E}= & \left\{\varepsilon_{i}\right\}+\left\{\varepsilon_{t}\right\}=\left\{\varepsilon_{i}\right\}+\frac{1}{3}\left[e^{-a t}+b\left(\frac{\sigma_{3}}{p_{\mathrm{a}}}\right)^{m}\right]\{I\} \\
& +\left[e^{-a t}+d \frac{S_{1}}{1-S_{1}}\right] \frac{\{S\}}{\sigma_{\mathrm{s}}} .
\end{aligned}
$$

5.2. Numerical Computation Model. Based on the Buxi Power Plant dam design, a finite element model was created. The model consists of 8222 grid elements and 9054 nodes, including 7774 dam-body elements and 8569 dam-body element nodes. The model is shown in Figure 14.

5.3. Calculation Conditions. To investigate and determine the cause of the fracturing near the temporary construction

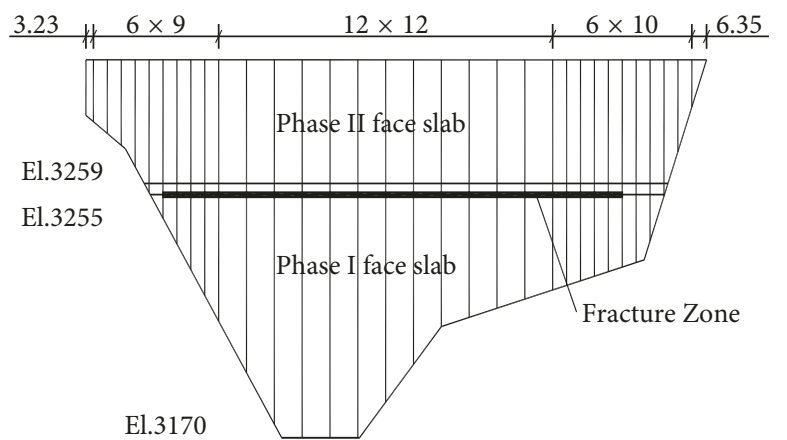

FIGURE 12: Location of slab fracturing in the phase I portion.

joint in the phase I concrete face, based on the above model and identical material parameters, the face stresses under three conditions when the water level is at $3283 \mathrm{~m}$ were calculated and subjected to comparative analysis.

The 3 conditions are as follows. Condition 1: on February 10, 2011, the dam filling reached its maximum. On April 13, 2011, concrete placement for the phase I face started, and the phase II face pouring was completed on November 17, 2011. In August 2012, the water level rose to the $3283 \mathrm{~m}$ elevation. Condition 2: On February 10, 2011, the dam filling reached its maximum. Placement of the phase I face spanned from April 14 to August 31, 2010. Placement of the phase II face spanned from April 13 to June 29, 2011; during the concrete placement stage, the reservoir stored no water. In August 


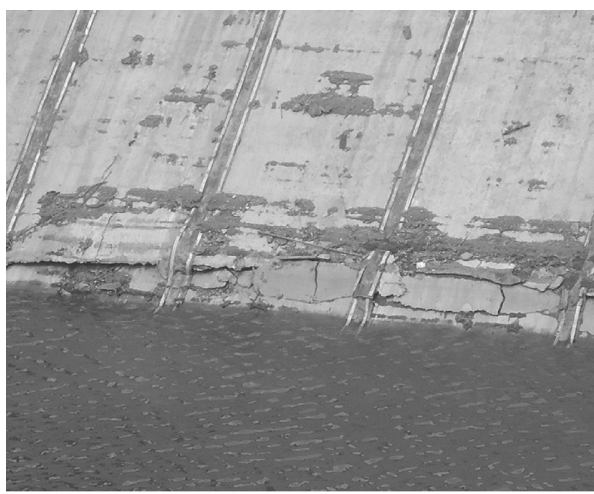

(a)

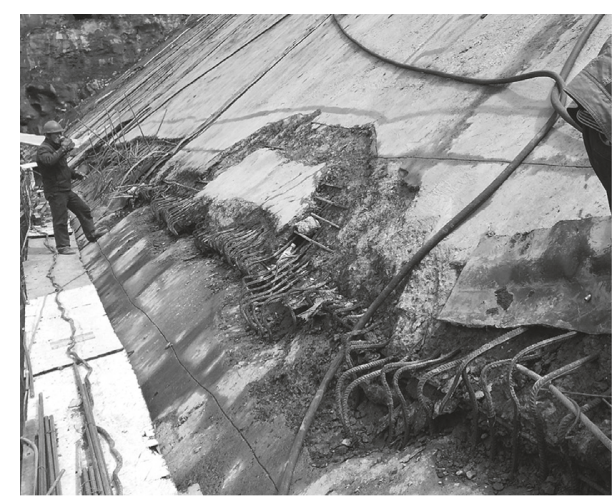

(b)

Figure 13: Local failure of the face in the phase I portion.

2012, the water level rose to the 3283 m elevation. Condition 3 is the same as condition 2, with the following exceptions: in October 2010, phase I reservoir impoundment started, and the water level rose to $3255 \mathrm{~m}$. In August 2012, the phase II stage II impoundment started, and the water level rose to the 3283 m elevation.

Shear stresses in the concrete face for comparative analysis are shown in Figures 15-19.

Figure 17 shows the shear stress in the concrete face in phase I on February 10, 2011, when the dam filling reached its maximum.

Based on the finite element results of three scenes, apart from scene 1 (Figure 15), during the rise of the reservoir water level, the slab of the staged construction shows a different degree of shearing stress at $3255 \mathrm{~m}$. If there is no water storage for upstream prior to the second-stage slab pouring, then the first-stage slab bears only the stress caused by filling the upper portion of the dam. When the reservoir water storage reaches $3283 \mathrm{~m}$, the maximum shear stress of the slab at $3255 \mathrm{~m}$ is approximately $-1.89 \mathrm{MPa}$, and the range is limited (Figure 16). However, if the reservoir stores water according to scene 3, then the first-stage slab is not only affected by the stress from the filling of the upper dam but also subjected to the upstream water load, resulting in large shear stress at an elevation of $3255 \mathrm{~m}$. When the reservoir water level rises to $3283 \mathrm{~m}$, the maximum shear stress at an elevation of $3255 \mathrm{~m}$ is approximately $-2.33 \mathrm{MPa}$, and there is a second shear stress region in the vicinity of $3243 \mathrm{~m}$ in elevation, and its maximum value is approximately $-1.84 \mathrm{MPa}$. The upper and lower shear stress regions form an "I" shape (Figures 17-19). This calculation result is similar to that of the first-stage slab crack shape of Shuibuya.

The maximum shear stress on the first-stage panel of two horizontal shear stress zones corresponds to the water level change diagram, as shown in Figure 20.

Figure 20 shows that the two horizontal shear stress values tend to increase as the reservoir water level rises. However, the increase in shear stress at an elevation of $3255 \mathrm{~m}$ is faster than at $3243 \mathrm{~m}$; that is, its shear stress will reach the ultimate shear strength value first and cause shear cracks, resulting in cracks on the concrete slab.
According to our analysis, stress transfer during upper dam filling and water pressure from a high reservoir water level are the primary causes of greater shear stress at $3255 \mathrm{~m}$ of elevation in sectioned construction and water storage (the water level of first-stage water storage is at $3255 \mathrm{~m}$, which is only approximately $4 \mathrm{~m}$ lower than that of the first- and second-stage temporary construction seams). Some stress has been generated within the first-stage concrete slab. Since the reservoir water level was not lowered in the second-stage slab construction, the stress of the first-stage slab has not been effectively reduced or eliminated; therefore, the internal stress of the first-stage slab has changed considerably as the water level of the second-stage water storage rises, and the shear stress value at $3255 \mathrm{~m}$ gradually increases. When the reservoir water level rises to a certain height, the strengthened shear stress causes shear failure at $3255 \mathrm{~m}$. The first-stage slab of Buxi Power Station is a single-layer steel reinforcement that has weak shear stress resistance. When the first-stage slab undergoes shear failure, due to the release of internal stress, the shear stress strength of the following layer is weakened, and second horizontal cracks such as those of Shuibuya will not occur. The moment that shear failure occurs under stress, the steel mesh located in the middle of the slab causes a large, brittle fracture of concrete through stress distribution.

According to the above analysis, even if the double-layer steel mesh is equipped according to the Shuabuya concrete slab, it might detract from the impact of shear stress from the concrete slab to a certain extent; however, because of a lack of antishearing reinforcement steel rib, cracks will still emerge.

\section{Structural Measures for an Anticrack Face Slab}

The above analysis indicates a certain degree of shear stress in the interior of the first-stage concrete slab during advanced construction and reservoir water storage. Its value is large, and therefore, Buxi Power Station, which is equipped with single-layer steel mesh, shows a wide range of shear damage. Although Shuibuya face slab, which is supplied with 


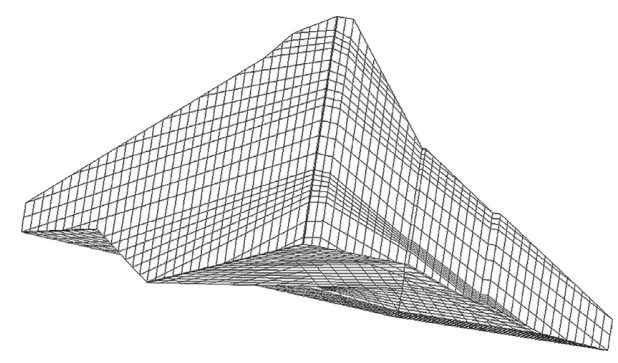

Figure 14: Dam finite element computation grid.

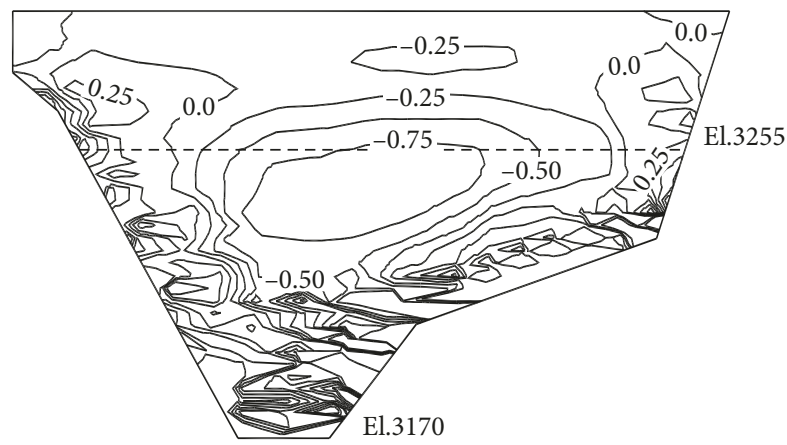

FIGURE 15: Shear stress in the concrete face under condition 1 with the water level at $3283 \mathrm{~m}$ (units: $\mathrm{MPa}$ ).

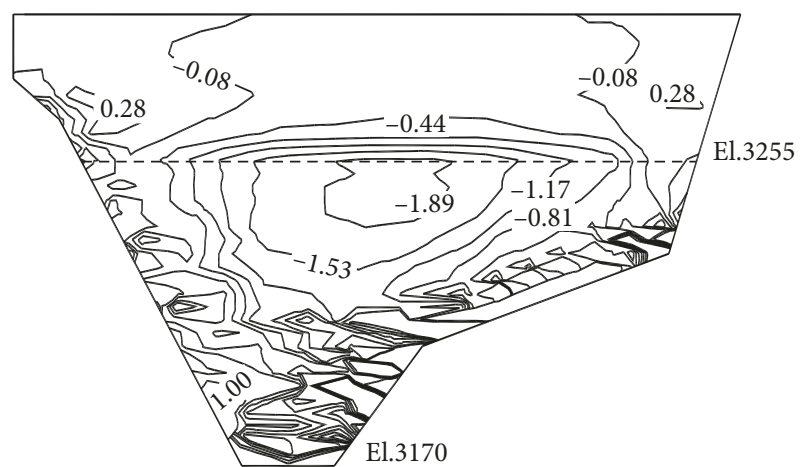

FIGURE 16: Shear stress in the concrete face under condition 2 with the water level at $3283 \mathrm{~m}$ (units: MPa).

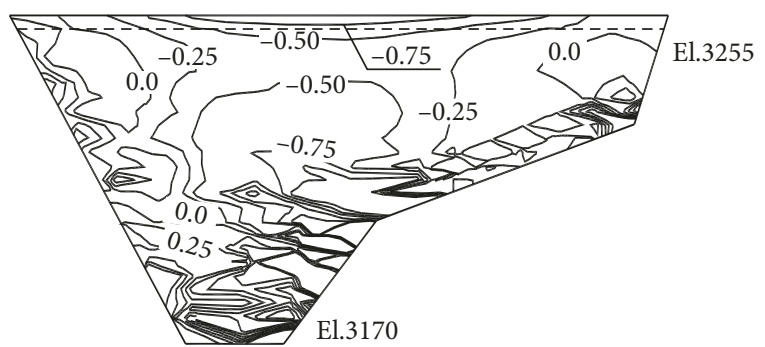

FIGURE 17: Shear stress in the concrete face under condition 3 with the water level at $3255 \mathrm{~m}$ (units: $\mathrm{MPa}$ ).

double-layer steel mesh, has not experienced large-scale shear failure, "I"-shape cracks still appear, so the effect of shear stress cannot be ignored.

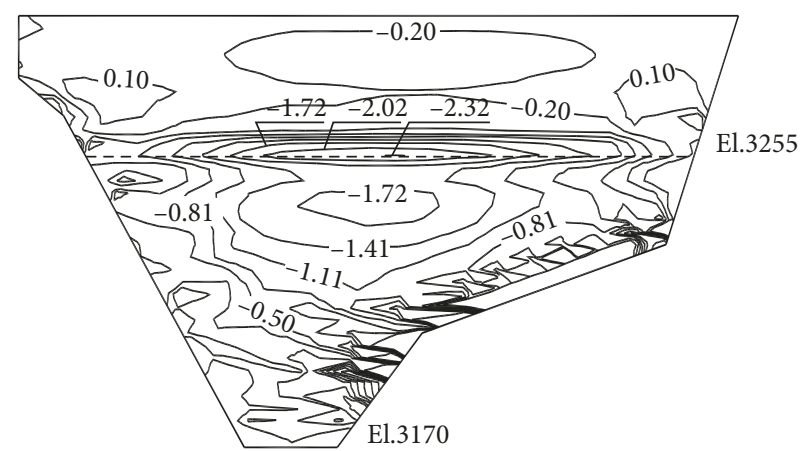

FIGURE 18: Shear stress in the concrete face under condition 3 with the water level at $3283 \mathrm{~m}$ (units: $\mathrm{MPa}$ ).

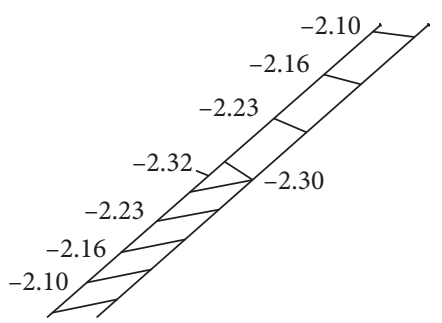

FIgURE 19: The partial shear stress section of the first stage panel under condition 3 (units: MPa).

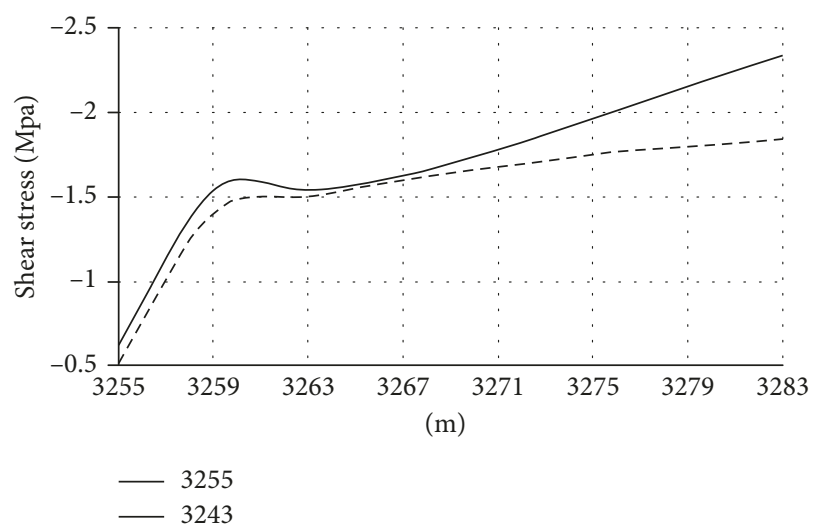

FIgURe 20: Diagram of maximum shear stress corresponding to change in the water level in two horizontal shear stress regions of the first-stage slab.

If the impact of shear stress on the concrete slab can be weakened, any appropriate method can be applied to reduce the probability of crack occurrence. Based on this concept, the corresponding structural measures proposed in this paper are described as follows:

(1) By comparing concrete slab cracks of Buxi Power Station with those of Shuibuya Power Station, in the case of advance slab construction and reservoir water storage, the first-stage concrete slab should be equipped with double-layer steel mesh to strengthen shear stress resistance. 
(2) Calculation reveals that if a large shear stress value is obtained, appropriate shear reinforcement steel rebar should still be arranged to increase the shear deformation resistant ability and reduce the probability of crack occurrence on the face slab.

(3) Prior to concrete pouring of the late-stage face slab, the reservoir water should be lowered to a certain level to allow the internal stress of the slab to be moderated and unleashed, thereby reducing the internal stress intensity of the first-stage face slab and the stress change during late-stage reservoir water storage.

(4) According to the monitoring data for the Buxi Power Station, although the concrete slab experienced a large, abrupt change, the subsequent monitoring data returned to normal, except for partial instrument reading failure, indicating that the duration of the abrupt change was relatively short, and the deformation tends to stabilize thereafter. Judging by the monitoring data alone, it is difficult to determine whether the slab has experienced shear failure. Therefore, the monitoring data will only serve as a basis for determination. Specific circumstances still need further analysis.

\section{Conclusions}

Due to their long construction period and sectioned filling, the flooding of high concrete-face rockfill dams during flood season is both predestined and inevitable. Because of demand in the case of flood and power generation, large stress occurred in the interior of the first-stage face slab during the advanced construction of the first-stage slab and reservoir water storage. Prior to second-stage slab pouring, if the internal stress of the first-stage slab cannot be effectively eliminated or reduced, it will increase along with the increase in the water level. The shear stress value in this range tends to increase gradually. Therefore, the application of a conventional design plan and construction method clearly cannot adapt to the deformation characteristics under force. The practical experiences of Buxi and Shuibuya Power Stations have undoubtedly provided important references for design and construction.

\section{Data Availability}

The data used to support the findings of this study are available from the corresponding author upon request.

\section{Conflicts of Interest}

The authors declare that they have no conflicts of interest.

\section{References}

[1] G. C. Jiang and Z. K. Zhao, 20-Year Review of Concrete-Face Rock-Fill Dams in China, China Water \& Power Press, Beijing, China, 2005.
[2] P. M. Filho and N. L. S. Pinto, "CFRD dam characteristics learned from experience," International Journal on Hydropower \& Dams, vol. 1, no. 1, pp. 72-76, 2005.

[3] W. Zhou and Y. Hu, "Rheological mechanism and long-term deformation forecast for a high concrete-face rock-fill dam," Journal of Hydraulic Engineering, vol. 38, no. 6, pp. 100-105, 2007.

[4] S. S. Neftali and R. P. Miguel, "In-plane transversal normal stresses in the concrete face of CFRD induced by the first-dam reservoir filling," Frontiers of Structural and Civil Engineering, vol. 12, no. 1, pp. 81-91, 2018.

[5] H. Q. Ma and F. D. Chi, "Technical progress on researches for the safety of high concrete-faced rockfill dams," Engineering, vol. 2, no. 3, pp. 332-339, 2016.

[6] Z. Wang, S. Liu, L. Vallejo, and L. Wang, "Numerical analysis of the causes of face slab cracks in Gongboxia rockfill dam," Engineering Geology, vol. 181, pp. 224-232, 2014.

[7] Y.-S. Kim, M.-W. Seo, C.-W. Lee, and G.-C. Kang, "Deformation characteristics during construction and after impoundment of the CFRD-type Daegok Dam, Korea," Engineering Geology, vol. 178, pp. 1-14, 2014.

[8] M. Y. Wang and B. Huang, "Long-term deformation characteristics of Shuibuya super-high concrete-face rock-fill dam," Journal of Hydroelectric Engineering, vol. 29, no. 4, pp. 167-172, 2011.

[9] P. X. Wang and W. J. Song, "Analysis of the measured settlement and prediction modeling of statistical settlement of Shuibuya CFRD," Journal of Hydroelectric Engineering, vol. 28, no. 4, pp. 81-86, 2009.

[10] H. F. Li and Y. Q. Zhang, "Creep test for rockfill," Journal of Hydroelectric Engineering, vol. 32, no. 1, pp. 212-217, 2013.

[11] H. H. Xiong and Y. Xu, "Analysis of face slab extruding rupture of high CFRDS," Journal of Hydroelectric Engineering, vol. 41, no. 1, pp. 27-30, 2015.

[12] G. Deng and X. G. Wang, "Study of conceptualization method of deformation pattern and horizontal breakage of face slab of concrete-face rockfill dam," Journal of Hydraulic Engineering, vol. 41, no. 1, pp. 396-404, 2015.

[13] J. J. Hua and W. Zhou, "Long-term deformation prediction of 300-m graded high rock-fill dam," Journal of Sichuan University, vol. 43, no. 3, pp. 33-38, 2011.

[14] Z. Y. Yang and G. C. Jiang, "Deformation control techniques for 200-m-high Hongjiadu concrete-face rockfill dam," Chinese Journal of Geotechnical Engineering, vol. 30, no. 8, pp. 1241-1247, 2008.

[15] J. R. He and J. Chen, "Research and application of concreteface anti-crack measure for Hongjiadu water power plant," Water Resource and Hydropower Engineering, vol. 36, no. 9, pp. 51-54, 2005.

[16] S. L. Yang and P. Zhong, "The influence of steel bars on crack extension in a concrete-face rock-fill dam," Journal of $\mathrm{Hy}$ droelectric Engineering, vol. 24, no. 5, pp. 45-48, 2005.

[17] Y. Arici, "Behaviour of the reinforced concrete face slabs of concrete faced rockfill dams during impounding," Structure and Infrastructure Engineering, vol. 9, no. 9, pp. 877-890, 2013.

[18] W. J. Song and Y. Sun, "Cause analysis and treatment of $1^{\text {st }}$ phase slab cracking of Shuibuya CFRD," Journal of Hydroelectric Engineering, vol. 27, no. 3, pp. 33-37, 2008.

[19] K. D. Chen, "Face deformation and stress analysis of concreteface rock-fill dam with multi-stage construction and impoundment," Water Resources and Electric Power, vol. 22, no. 2, pp. 1-8, 1995.

[20] W. Zhou, J. J. Hua, X. Chang, and C. Zhou, "Settlement analysis of the Shuibuya concrete-face rockfill dam," Computers and Geotechnics, vol. 38, no. 2, pp. 269-280, 2011. 
[21] B. Xu, D. Zou, and H. Liu, "Three-dimensional simulation of the construction process of the Zipingpu concrete face rockfill dam based on a generalized plasticity model," Computers and Geotechnics, vol. 43, pp. 143-154, 2012.

[22] H. Z. Guo, "Filling construction technology for concrete face rockfill dam of Buxi Hydropower Station," Sichuan Water Resources, vol. 4, pp. 15-16, 2011.

[23] Z. Z. Liu and B. Z. Liu, "Construction of concrete face slab for rockfill dam of Buxi hydropower station in Yazui river," Sichuan Water Resources, vol. 2, pp. 6-7, 2011.

[24] Z. J. Shen, "Creep model of rock-fill material and its application," Sichuan Water Resources, vol. 4, pp. 335-342, 1994.

[25] Y. Z. Zuo and Z. L. Cheng, "Research on creep test method of rockfill material," Journal of Yangtze river Scientific Research Institute, vol. 12, pp. 63-65, 2009.

[26] W. Zhou and X. L. Chang, "Creep analysis of high concretefaced rockfill dam," International Journal for Numerical Methods in Biomedical Engineering, vol. 11, pp. 1477-1492, 2010.

[27] P. Pramthawee, P. Jongpradist, and R. Sukkarak, "Integration of creep into a modified hardening soil model for timedependent analysis of a high rockfill dam," Computers and Geotechnics, vol. 91, pp. 104-116, 2017. 


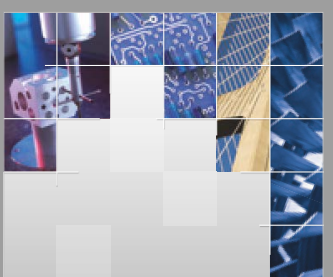

\section{Enfincering}
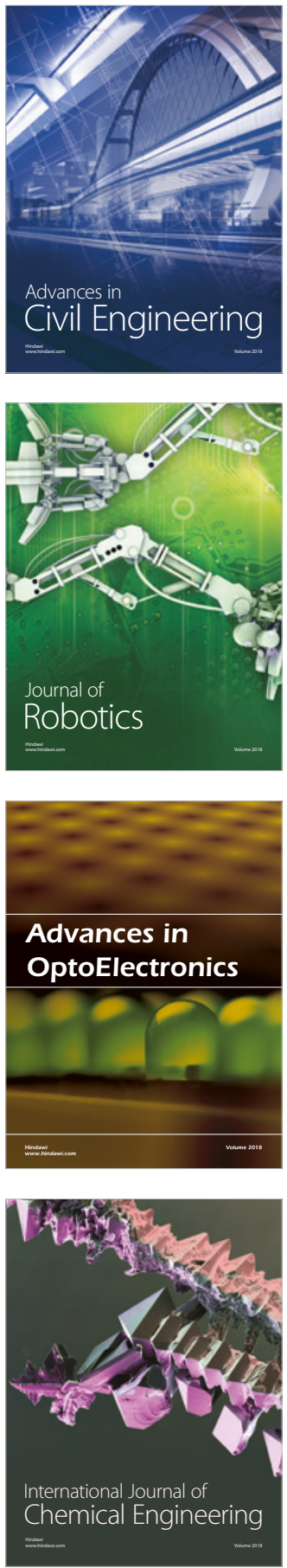

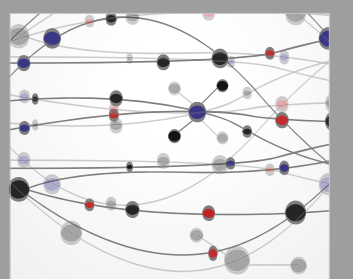

\section{Rotating \\ Machinery}

The Scientific World Journal

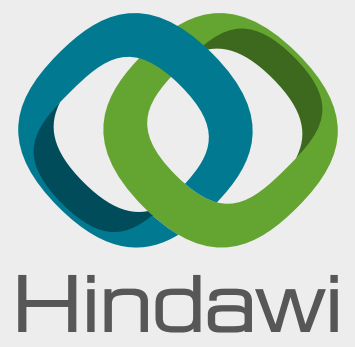

Submit your manuscripts at

www.hindawi.com
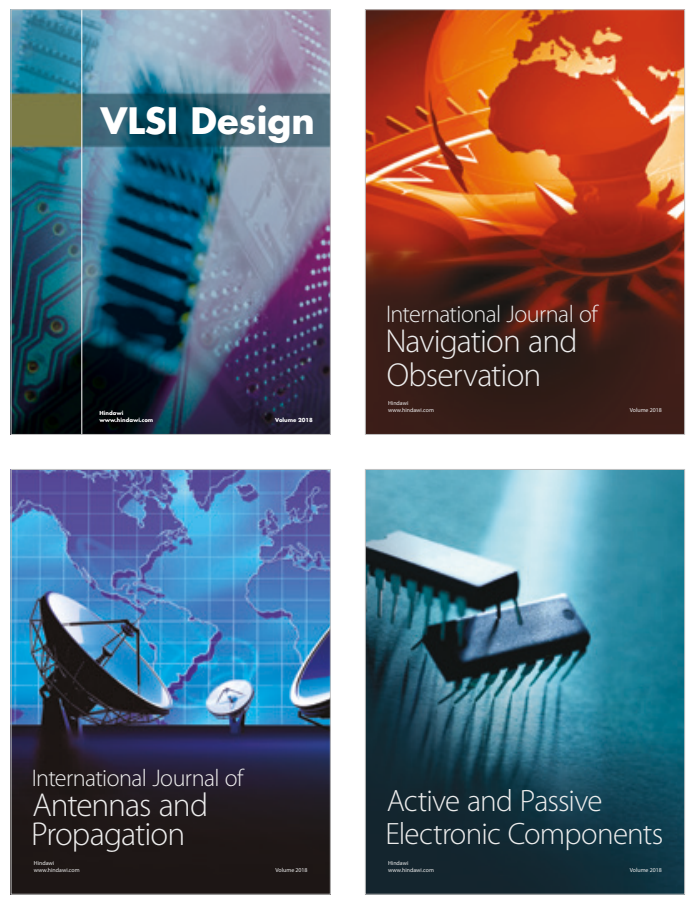
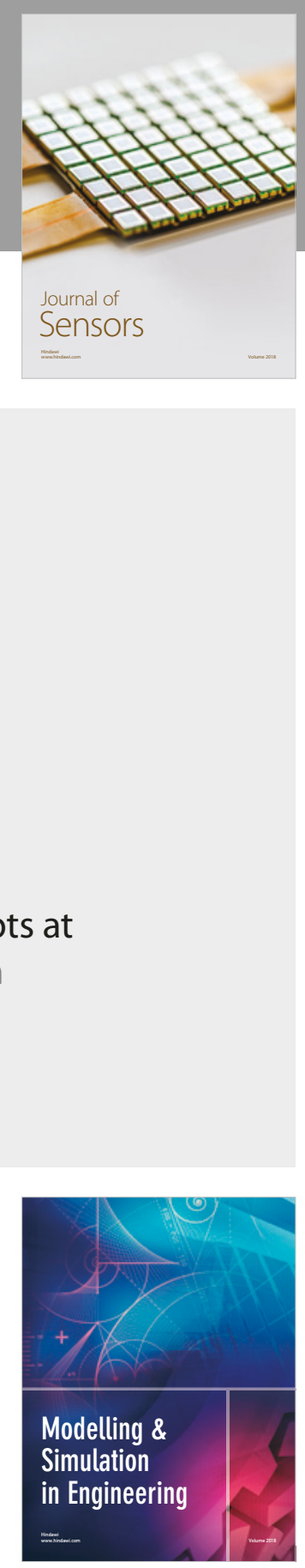

\section{Advances \\ Multimedia}
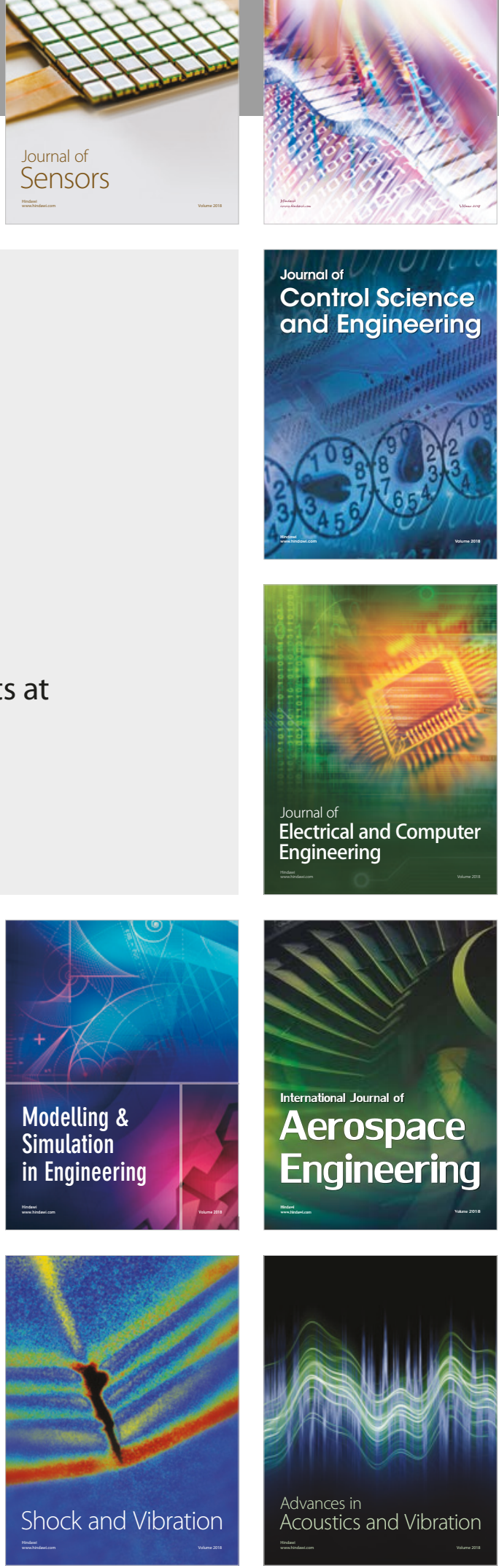